\title{
20912 伝達特性変更のための振動エネルギー解析に関する基礎的検討
}

\author{
Vibration Energy Analysis for Controlling Vibration Transfer Characteristic
}

\author{
○正 北原 篤（首都大院） 正 吉村 卓也（首都大） \\ Atsushi KITAHARA and Takuya YOSHIMURA
}

Tokyo Metropolitan University, 1-1 Minamiosawa, Hachioji, Tokyo

\begin{abstract}
This paper investigates on structure vibration energy (intensity) when the structure has high damping characteristics. A plate structure modeled by finite element approach is used as an example. Vibration energy reduction by modifying mass distribution is estimated. Then distribution of structural intensity in order to reduce vibration is evaluated. At the structure with material damping, vibration energy spreads over the structure with dissipating energy. When vibration energy is low, structural intensity and inflow energy is small. And when intensity stays with making vortex, it is supposed that vibration level increase. In order to decrease vibration, we suppose that making intensity strait is effective.
\end{abstract}

Key Words: Forced Vibration, Structural Intensity, Vibration Energy Flow

\section{1. 緒言}

構造物における振動の伝達や散逸の効率的な制御には，振 動エネルギーの可視化が有効であり，その手法として振動イ ンテンシティ ${ }^{(1)(2)}$ が提案されている. しかし，振動インテン シティの分布形状と振動レベルとの関係は, 未だ明確にされ ているとは言い難い. 文献(3)では，振動インテンシティのモ 一ド展開が提案されているが, 減衰が微小で単一モードが支 配的な共振点を主眼としている.モード密度が高い中周波帯 域や，減衰が大きい高分子材料を視野に入れると，固有モ一 ドに依存しない対策も重要となる．また，ダンパによるイン

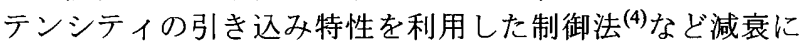
関する研究事例もあるが, 対象構造物自体が高減衰である場 合の研究は少ない.

そこで本研究では, 高減衰を有する構造物における振動エ ネルギーの伝達特性に着目する．質量分布の変更により生じ る振動エネルギー変化を評価し，振動抑制が可能なインテン シティ分布について基礎的検討を行う.

\section{2. 振動エネルギーの解析方法}

調和加振力を受ける, $x y$ 平面上の平板の曲げ振動を対象に, 振動エネルギーの解析方法を示す.

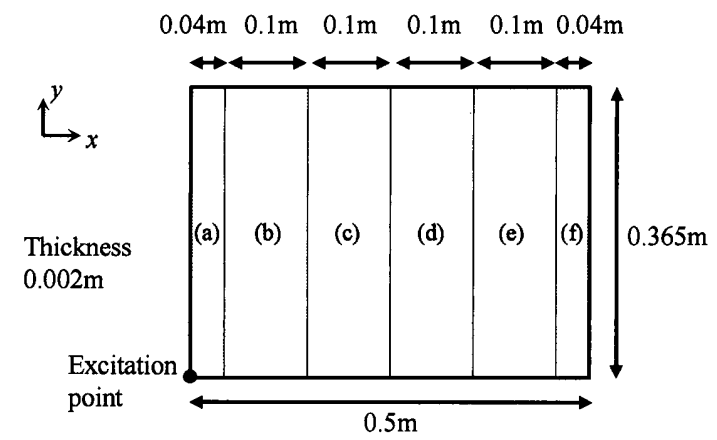

Fig.1 Plate model

\section{1 振動インテンシティ}

平板の曲げ振動において， $x$ 方向の振動インテンシティの 周期平均 $I_{x}$ は, $x$ 軸に垂直なある単位断面を単位時間に通過 するエネルギーとして, 次式で定義される.

$$
I_{x}(x, y, \omega)=\frac{1}{2} \operatorname{Re}\left[-j \omega\left(N w^{*}+M_{y} \theta_{y}{ }^{*}+M_{x y} \theta_{x y}{ }^{*}\right)\right]
$$

ただし，Re[]は実部， $j$ は虚数単位， $\omega$ は角振動数， $N$ は面 外せん断力, $w$ 注面外変位, $M_{y}, \theta_{y}$ はそれぞれ $y$ 軸まわりの 曲げモーメントと回転変位, $M_{x y}$ はね ねじりモーメント， $\theta_{x y}$ は ねじり変位， *恃複素共役である. $y$ 方向の振動インテンシテ イについても同様に定義される.

(1)式に関して, 弾性体の構成式を利用して変位のみで表す 方法 ${ }^{(3)}$ も提案されているが，3 階の空間微分が必要であり, 誤差が生じやすい，そこで本研究では，有限要素法で求まる 内力を用いて(1)式を算出する. 平板のある点に角振動数 $\omega$ の調和加振力が作用した際の, 全節点の定常応答の複素振幅 ベクトル uのうち, 任意の要素 $i$ に含まれる節点変位を $\mathbf{u}_{i}$ とすると, 要素 $i$ の各節点における内力 $\mathbf{f}_{i}$ は, 質量, 減衰, 剛性の各要素行列 $\mathbf{M}_{i}, \mathbf{C}_{i}, \mathbf{K}_{i}$ を用いて

$$
\mathbf{f}_{i}=\left[-\omega^{2} \mathbf{M}_{i}+j \omega \mathbf{C}_{i}+\mathbf{K}_{i}\right] \mathbf{u}_{i}
$$

により求めることができる.

\section{3 定常振動エネルギー}

本研究では, 振動低減を評価する指標として, 平板全体の 定常振動エネルギーを用いる. 定常状態におう的振動エネル ギーの周期平均 $E$ は, 歪エネルギー $E_{U}$ と運動エネルギー $E_{K}$ の和として，次式で表わされる.

$$
\begin{aligned}
& E=E_{U}+E_{K} \\
& E_{U}=\frac{1}{4}\left[\operatorname{Re}[\mathbf{u}]^{T} \mathbf{K} \operatorname{Re}[\mathbf{u}]+\operatorname{Im}[\mathbf{u}]^{T} \mathbf{K} \operatorname{Im}[\mathbf{u}]\right] \\
& E_{K}=\frac{\omega^{2}}{4}\left[\operatorname{Re}[\mathbf{u}]^{T} \mathbf{M} \operatorname{Re}[\mathbf{u}]+\operatorname{Im}[\mathbf{u}]^{T} \mathbf{M} \operatorname{Im}[\mathbf{u}]\right]
\end{aligned}
$$

\section{3. 対象とする平板}

図 1 に示寸鋼製，周辺自由の長方形平板を対象とし，材料 減衰を剛性比例のレイリー减衰で与える．仮想的に，鋼材よ りも高減衰に設定している，外力は，図の左下点に，面直方 
向に振幅 $1 \mathrm{~N}$ の調和加振力が作用するものとする.

この平板において，領域(a) (f)ごとに密度を変化させた際 の振動エネルギー変化, およびその状態における振動インテ ンシティを評価することにより，振動抑制を達成可能なエネ ルギー流れについて基礎的検討を行う.

\section{4. エネルギー流れの解析結果}

4.1 振動エネルギー変化

図 1 の領域(b), および領域(e)をそれぞれ密度 2 倍に変化 させた際の, 平板全体の定常振動エネルギーの周波数応答を 図 2 に示す.

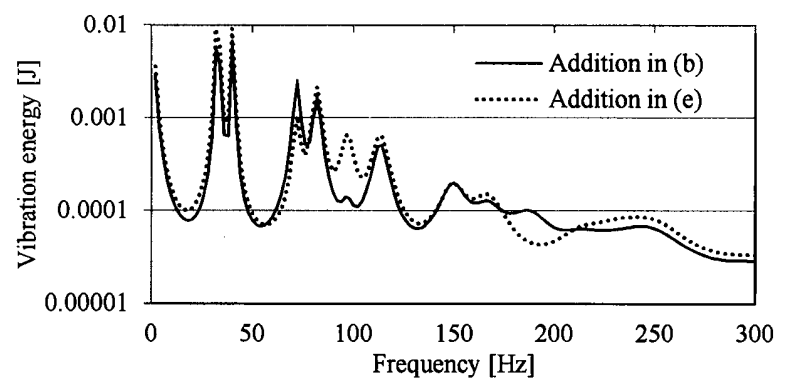

Fig.2 Vibration energy

図 2 より，97Hz と $235 \mathrm{~Hz}$ では領域(b)に，180Hz では領域 (e)に，それぞれ質量を付加することで振動エネルギーが低減 されていることが分かる. そこで，これらの周波数における 振動インテンシティを評価する.

\section{2 振動インテンシティの評価}

振動エネルギー変化が特徴的であった前述の3つの周波数 について, 領域(b)と(e)の密度をそれぞれ 2 倍にした際の振 動インテンシティを図 3 5 に示す. 矢印はインテンシティの 大きさと方向を表している. 左下の加振点から流入した振動 エネルギーが，材料減衰による散逸を伴いながら，平板全体 へと伝播している様子が可視化できている.

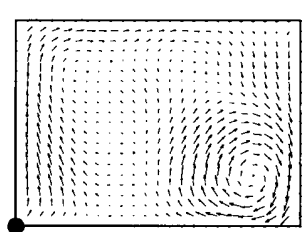

Addition in area (b)

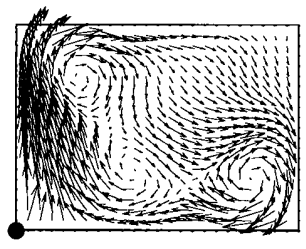

Addition in area (e)
Fig.3 Structural intensity at $97 \mathrm{~Hz}$

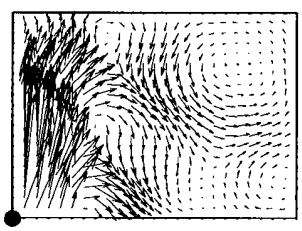

Addition in area (b)

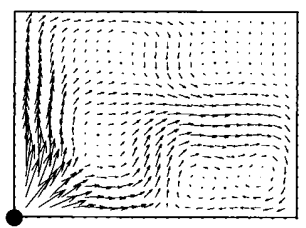

Addition in area (e)
Fig.4 Structural intensity at $180 \mathrm{~Hz}$

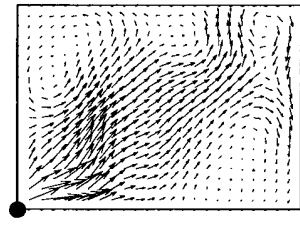

Addition in area (b)

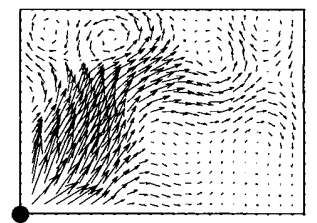

Addition in area (e)
Fig. 5 Structural intensity at $235 \mathrm{~Hz}$

質量付加位置の違いを比較すると，いずれの周波数におい ても, 振動エネルギーが小さいケースのほうが, インテンシ ティも小さい. 加振による流入エネルギーも抑制されている ものと考えられる.

更に, 振動インテンシティの分布形態に着目すると, 振動 エネルギーが大きいケースでは, 渦状に循環する流れが形成 されてエネルギーの停留が生じている. 逆に, 振動エネルギ 一が小さいケースでは, 左下の加振点から右上方向にスムー ズにエネルギーが流れる傾向が見られる. 流れのスムーズさ について, 各節点のインテンシティ $\mathbf{I}_{n}$ の, 系全体量に占める 有効量の割合 $y$ を下記の式(6)で定量化する.||はベクトルの 大きさを表す．算出結果を図 6 に示す.

$$
\gamma=\frac{\left|\sum_{n} \mathbf{I}_{n}\right|}{\sum_{n}\left|\mathbf{I}_{n}\right|}
$$

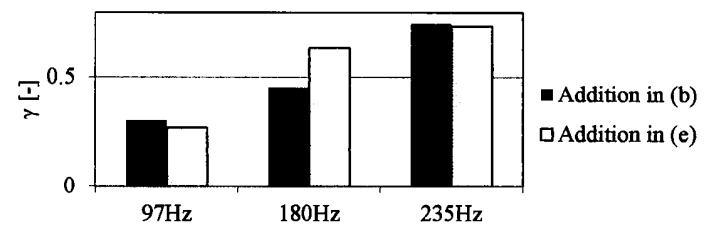

Fig.6 Smoothness of intensity distribution

差が明確でない周波数もあるが，振動エネルギーが小さい ほど $\gamma$ が大きい傾向が確認できた. これより，平板全体の振 動抑制のためには, 循環させず, ストレートに伝搬していく インテンシティの分布が適しているものと推測する.

本仮説の検証, および狙いのインテンシティ分布を実現す る手法の検討については，今後の課題である.

\section{5. 結言}

1)FEM の内力を用いたインテンシティの算出により, 材料減 衰を有する構造物において，流入したエネルギーが散逸を伴 いながら伝播していく様子を可視化できる.

2)振動が小さい場合は，振動インテンシティや流入エネルギ 一も小さい.

3)振動抑制のためには，循環を形成させずにストレートに伝 搬するインテンシティ分布が適していると推測される。

\section{参考文献}

(1) D. U. Noiseux, Journal of Acoustical Society of America, 47 (1970), 238-247.

(2) G. Pavić, Journal of Sound and Vibration, 49 (2) (1976), 221-230.

(3) 山崎徹 ら, 日本機械学会 Dynamic and Design Conference CD-ROM 論文集, (2007), No. 618

（4）須田 祥平ら, 可視化情報, 32-2 (2012), 255-256 